\title{
A SURVEY FOR ASSESSING THE KNOWLEDGE OF TRANSFUSION MEDICINE AMONGST RESIDENT DOCTORS
}

Mehra Ruhi', Gupta Seema²

${ }^{1}$ Post Graduate Resident, Department of Immunohaematology \& Blood Transfusion, MGM Medical College \& Hospital, Kamothe, Navi Mumbai, Maharashtra.

${ }^{2}$ Associate Professor \& In-charge Blood Bank, Department of Immunohaematology \& Blood Transfusion, MGM Medical College \& Hospital, Kamothe, Navi Mumbai, Maharashtra.

\section{ABSTRACT}

\section{BACKGROUND}

Blood transfusion is an essential part of patient's care. Blood is an expensive and limited resource. Knowledge of physicians regarding indications for transfusion and the dose of blood and blood products has an important impact on optimal use of blood and blood products.

\section{AIMS}

The objective behind this study was to assess the knowledge regarding transfusion medicine among the residents of our institute and to find out the deficient areas where there is scope for improvement.

\section{SETTINGS AND DESIGN}

Hospital based prospective study.

\section{METHODS}

A simple objective type of questionnaire was prepared and distributed amongst the residents. The filled questionnaires were evaluated through a marking scheme devised for this purpose by experts in the field of transfusion medicine.

\section{STATISTICAL ANALYSIS}

Statistical analysis of data was performed using the Statistical Package for the Social Sciences (SPSS) software Version 16.0. Discrete categorical data were presented as n (\%). Continuous data were given as mean.

\section{RESULTS}

$42.6 \%$ of the questions were answered appropriately. The level of awareness amongst the residents correlated with their subspecialty. Internal medicine residents, paediatricians and anaesthetists received the best test scores. The mean score of knowledge was higher among participants who had received some training regarding transfusion medicine during their undergraduate medical course.

\section{CONCLUSION}

We can conclude from our study that the current knowledge of physicians and medical post graduate residents regarding transfusion medicine is lacking at many aspects and needs to be updated. There is a need to implement fundamental changes in the current teaching curriculum of medical students.

\section{KEYWORDS}

Blood Transfusion, Knowledge, Lacking, Resident Doctors, Transfusion Medicine.

HOW TO CITE THIS ARTICLE: Ruhi M, Seema G. A survey for assessing the knowledge of transfusion medicine amongst resident doctors. J. Evolution Med. Dent. Sci. 2016;5(31):1600-1605, DOI: 10.14260/jemds/2016/377

\section{INTRODUCTION}

Blood is a limited resource and an expensive commodity, which must be used judiciously. An essential part of patient's care and one of the most common procedures performed in hospitals now-a-days is blood transfusion.

Financial or Other, Competing Interest: None.

Submission 27-02-2016, Peer Review 22-03-2016,

Acceptance 28-03-2016, Published 15-04-2016.

Corresponding Author:

Dr. Ruhi Mehra

Flat No - 101, $1^{\text {st }}$ Floor,

Andheri Kamla C.H.S. Ltd. Kul Kudos,

Patil Lane, Off J. P. Road, Behind Raj Oils,

Opposite Navrang Theatre,

Andheri West, Mumbai-400058.

E-mail: ruhi_mehra321@yahoo.co.in

DOI: $10.14260 /$ jemds/2016/377
Transfusion of blood or its components can be at times life-saving. Along with its advantages, there are a few disadvantages of blood transfusion too. There is a potential risk of acute or delayed complications like immunosuppression, Transfusion-Related Acute Lung Injury (TRALI), Graft Versus Host Disease (GVHD), etc. Although the transmission risk of transfusion related infections like HIV, Hepatitis has decreased, the potential threat still exists. So blood and its components should be prescribed only to treat conditions that cannot be prevented or managed effectively by alternative means.

The need to ensure the appropriateness of blood transfusion has long been recognized.[1] Decision to prescribe blood and blood products is made by the physician and his knowledge is one of the key elements, which determine the effectiveness of any blood transfusion system. Knowledge of physicians regarding indications for transfusion and the 
appropriate amount of blood and blood products has an important impact on the optimal use of blood and blood components.[2] The increasing preparation cost of blood components, cost-ineffectiveness of diagnostic tests and resource constraints place unfavourable impact on the quality of services.[3] Physician's knowledge toward blood transfusion is an extremely important issue.[3] One of the methods to reduce the irrational blood use is to practice interventions and provide training to physicians. ${ }^{4]}$

The medical curriculum of undergraduate medical studies does not provide any specific training regarding transfusion medicine. The entrance exams to be cleared for getting admission into post-graduate courses too do not focus much on the blood transfusion aspects of medical science. Only in Germany and India is transfusion medicine a recognized super-specialty. In most other countries like The United States and some European countries, it is a subspecialty of other disciplines like haematology, internal medicine, paediatrics, etc.[5] Improvement in the current status of transfusion medicine education can only be done by first obtaining a baseline level of knowledge and identifying the gaps in this knowledge. This could be achieved by conducting a survey focused on the basic knowledge and clinical use of blood and blood products. The current survey was conducted to identify deficiencies in the education of residents regarding transfusion medicine and to identify whether additional training is required or not.

\section{MATERIAL AND METHODS}

This study was conducted by the Department of Immunohematology and blood transfusion of Mahatma Gandhi Mission's Medical College and Hospital, Navi Mumbai in 2015. The participants were post graduate students in various clinical subspecialty such as internal medicine, surgery, paediatrics, dermatology, anaesthesiology, urology, obstetrics, cardiology, emergency medicine, ENT, geriatric medicine, etc. A multiple choice strategy for the evaluation of resident's knowledge was chosen because it could be implemented rapidly, is objective and is cost-efficient, although it has the disadvantage of being influenced by stimulate recall and may not adequately evaluate higher cognitive functions.[5]

A questionnaire was developed based on the American Association of Blood Banks Technical Manual (American Association of Blood Banks, 1996) as a reference source. It solicited information as follows-Demographic information (Age, sex, graduation medical university, year of graduation, years of practice, current subspecialty), knowledge regarding characteristics and contents of blood products, basic clinical knowledge of blood transfusion (Past experience of prescribing blood and blood products, indications and contraindications for transfusions of PRBC, platelets, FFP, cryoprecipitate, saline washed PRBCs), blood administration technique, adverse reactions of blood transfusion and their management, criteria for storage of blood and blood products, blood donation status (Donated earlier or not, how often, criteria for blood donation), whether they had received any education regarding transfusion medicine earlier, suggestions for improving physician's knowledge regarding blood transfusion. For most questions only a yes, a no or a short answer was required. The questionnaire has been included for reference.
Residents from all specialties were invited and briefed about the protocol of the study. Questionnaires were distributed and filled questionnaires were collected back for evaluation. Papers were evaluated by concerned experts in the field of transfusion medicine. The key for the questionnaire was developed in accordance with AABB and WHO guidelines. Each correct answer scored one mark, while an incorrect answer scored zero, partially correct answers scored half a mark. The total weightage of the questionnaire was 30 marks. Each domain consisted of series of questions, which were evaluated systematically and marks were allotted accordingly.

\section{ETHICS}

This study was approved by the Ethical Review Committee of the Institute. Participants were briefed about the study and their consent was obtained.

\section{STATISTICS}

Statistical analysis of data was performed using the Statistical Package for the Social Sciences (SPSS) Software Version 16.0. Discrete categorical data were presented as $\mathrm{n}$ (\%). Continuous data were given as mean.

\section{RESULT}

One hundred and two residents participated in the study and answered the questionnaire. Mean age of the participants was 28.6 years (Range $24-35$ years); $74.51 \%$ of the participants were male, while $25.49 \%$ were females. The average experience of participants was 2.5 years (Range 1-8 years). Prior experience of prescribing blood and blood products was $83.9 \%$ among the residents; $38.23 \%$ residents stated they had received training regarding transfusion medicine in medical school, but among them $78.2 \%$ found this to be inadequate. Around $49.2 \%$ had experience of donating blood earlier.

The most frequent responses $22 \%$ were from the residents of internal medicine, followed by anaesthetists, paediatricians and orthopaedicians. Overall, $42.6 \%$ of the questions were answered appropriately. The average score among the participants was $12.3(6-20)$ out of 30 . Out of all $75.7 \%$ participants scored less than 15 marks, while $24.3 \%$ scored over 15 marks. Questions regarding basic clinical knowledge of blood and blood products were answered correctly by $23.6 \%$ participants. Questions regarding administration and adverse reactions of blood transfusions were answered correctly by $38.3 \%$ participants. Questions concerning storage of blood and blood products were the most poorly answered questions by majority of the participants.

The level of awareness among the residents correlated with their subspecialty $(\mathrm{P}<0.05)$. Internal medicine residents, paediatricians and anaesthetists received the best test scores [Figure 1] and [Table 1]. The knowledge score varied according to years in practice, knowledge of those with less than 5 years in practice was assessed to be higher. The knowledge score was found to be equal among males and females. The average knowledge score did not differ between residents who had recently prescribed blood than with those who had been prescribed in the past $(\mathrm{P}=0.13)$. The mean score of knowledge was higher among participants who had 
received some training regarding transfusion medicine during their undergraduate medical course $(\mathrm{P}<0.01)$.

The knowledge score regarding the criteria for blood donation was higher in residents who had a previous history of donating blood; $92.4 \%$ of the participants were of the opinion that additional educational programs are required to improve the knowledge regarding transfusion medicine. Training during internship program in medical school, educational CME's, official seminars, informative brochures were some of the suggestions provided by the residents for improving the prevailing knowledge regarding transfusion medicine.

\section{DISCUSSION}

Necessity is the most important element for any changes to be made.[4] Education is the first of the six general methods of changing physician behaviour as described by Greco and Eisenberg.[6] Bryant et al. 2005 showed that it is the responsibility of transfusion medicine specialists in therapy centres to audit and monitor the clinical aspects of blood transfusion in hospitals.[7]

Knowledge level of physicians is one of the key points in determining the efficiency of any blood transfusion service.[8] Training of physicians plays a major role in management of blood usage, since human errors are involved in the risks of blood transfusion therapy.[9] Studies carried out by Mozes et al.[10] Surgenor et al.[11] and Goodnough et al.[12] since the onset of the Acquired Immunodeficiency Syndrome (AIDS) epidemic have found that there is still considerable inappropriate use of blood products. Correlation between physicians' knowledge, usage of blood components and the inappropriate use of blood products have been demonstrated in studies conducted by Salem-Schatz et al.[13] Some studies conducted by Wu et al.[14] Hebert and Fergusson.[15] Rao et al.[16] have indicated of a definite correlation between blood transfusion and the morbidity/mortality rate. Rothschild et al.[3] concluded that although blood transfusion is life-saving, it is associated with significant risks. These risks are mostly known, but there are still cases attributed to inappropriate and unnecessary administration of blood.

Our study proved that the knowledge of residents regarding transfusion medicine and blood transfusion practices is not up to the required standards. This leads to improper use of blood and blood products, more costs per patient and the exposure of patients to infectious and noninfectious adverse consequences.[2,8,10,11,13,17] Significant advances in internal medicine and aggressive surgeries have led to remarkable increase in use of blood and blood components. However, many of the physicians are still unaware regarding the emergency blood transfusion protocols and massive blood transfusion protocols. The residents should be aware regarding the newer techniques in blood transfusion like leukocyte depleted blood products, irradiated blood products, apheresis procedures and blood substitutes. Impact of blood transfusion on immune system, adverse effects of blood transfusion-their clinical presentation, reporting and management are the domains where still knowledge is lacking among the residents.

The result of our study was comparable with the study conducted in Iran by Gharehbaghian et al.[2] which reported that 1,242 specialists had a lower level of knowledge regarding transfusion medicine than they had been expected and improvement in physicians' knowledge led to a decrease in unnecessary transfusion and improves blood sufficiency for patients. Likewise, in their study, Salem-Schatz et al.[18] reported that only about one-third of physicians had enough knowledge about the correct use of blood and blood products. Another study conducted by Rock et al.[8] identified the poor basic knowledge of physicians regarding blood transfusion. These findings are in line with the results of our study, which indicate that $75 \%$ of the residents believed that they received insufficient education regarding transfusion medicine and as a result of this they felt less competent in transfusion medicine and were aware of their weaknesses in the care of patients. The findings of this study also revealed that $92.4 \%$ of residents believed that there is a need for more education concerning transfusion medicine. This finding was similar to other studies in which physicians stated that they require more training regarding transfusion medicine. $[2,8,19,20]$

The study conducted by Salimi.[21] indicated that the knowledge level of MD graduates is much less than expected; more than $80 \%$ declared that they had passed no courses on blood transfusion. Medical students during their undergraduate and residency courses are not provided with any official or academic training regarding blood transfusion. There is no recognized system of examination for advanced subspecialty training in transfusion medicine. Blood transfusion is still practiced traditionally by practitioners and they are largely unaware of new developments in transfusion medicine. Our study indicated that the medical students, resident medical officers and physicians of different clinical disciplines require further training in blood transfusion similar to that shown in the study conducted by Mitchell et al.[19] Since then, researchers have made endeavours to formulate a comprehensive and integrative programme of transfusion medicine education.

Educational programs are required to improve blood transfusion knowledge among the medical students. Integrating transfusion medicine education at undergraduate level is mandatory. During their internship, the students should have a compulsory posting in the hospital blood bank in order to understand the functioning and importance of blood banking. Practical and theoretic educational credits of transfusion medicine should be offered during residency and general medicine courses. Continuing in-service medical education programs covering the clinical implication and practical aspects of transfusion medicine should be arranged for the physicians and surgeons on a regular basis. Teaching programme for transfusion medicine experts should be developed more in order to train them in accordance with the present standards of healthcare and hospitality.

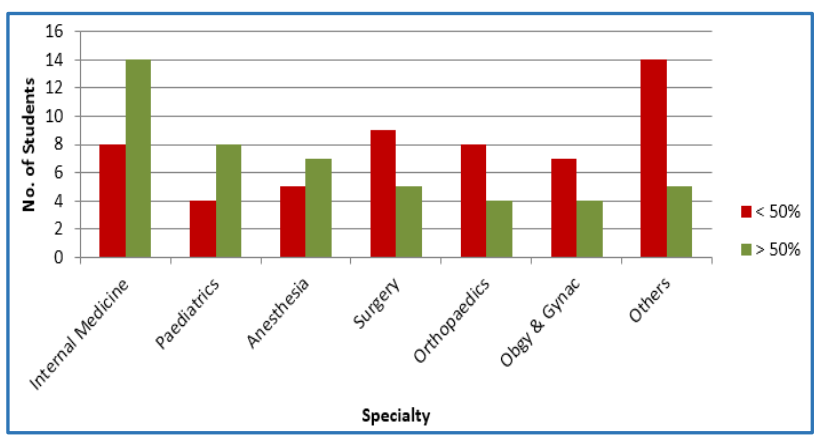

Fig. 1: Trends in Score Distribution amongst Various Specialties 


\begin{tabular}{|c|c|c|}
\hline \multirow[t]{2}{*}{ Specialty } & \multicolumn{2}{|c|}{$\begin{array}{c}\text { No. of Students } \\
\text { \& their Marks Obtained in } \\
\text { Percentage }\end{array}$} \\
\hline & $<50 \%$ & $>50 \%$ \\
\hline Internal Medicine & 8 & 14 \\
\hline Paediatrics & 4 & 8 \\
\hline Anaesthesia & 5 & 7 \\
\hline Surgery & 9 & 5 \\
\hline Orthopaedics & 8 & 4 \\
\hline $\begin{array}{l}\text { Obstetrics \& } \\
\text { Gynaecology }\end{array}$ & 7 & 4 \\
\hline Others & 14 & 5 \\
\hline Total & 55 & 47 \\
\hline $\begin{array}{r}\text { Table 1: } \\
\text { Stude }\end{array}$ & $\begin{array}{l}\text { tribu } \\
\text { rious }\end{array}$ & \\
\hline
\end{tabular}

\section{CONCLUSION}

Transfusion medicine knowledge among the residents and physicians is required for appropriate clinical use of blood and blood products. We can conclude from our study that the current knowledge of physicians and medical post graduate residents regarding transfusion medicine is lacking at many aspects and needs to be updated. It is necessary for residents, especially of the disciplines mostly relevant to blood transfusion to take specialized courses on transfusion medicine. There is a need to implement fundamental changes in the current teaching curriculum of medical students. Specialist training is the key element in reduction of blood wastage and is the best way for safety of blood recipients to be maintained. Formulation of new policies in the field of transfusion medicine education and training would help in overcoming the shortfalls in the supply of blood and blood products in the forthcoming decades.

\section{ACKNOWLEDGEMENT}

We thank the Mahatma Gandhi Mission's University for their permission for conducting this study, generous help with data collection and for holding the seminars for the post-graduate resident doctors.

\section{KNOWLEDGE OF RESIDENT DOCTORS CONCERNING TRANSFUSION MEDICINE}

Name:

Age:

Sex:

Marital Status:

Graduation Medical University:

Year of Graduation:

Years of Practice:

Course (Specialty):

\section{Blood donation status}

A. Have you donated blood before?

B. How often have you donated?

\section{Education regarding transfusion medicine}

A. Have you received any education?

B. Was the education given sufficient for you?

C. Any suggestion for improving the knowledge

D. Have you prescribed blood/component transfusion in your practice?
E. What is your experience regarding blood transfusion?

3. Fill the following selection criteria for a blood donor

A. Age: (i) $16-60$ Yrs. (ii) $20-50$ Years. (iii) $18-65$ Years (iv) 17-55 Years.

B. Min Hb: (i) $>12.5 \mathrm{~g} / \mathrm{dL}$ (ii) $>13.5 \mathrm{~g} / \mathrm{dL}$ (iii) $>14.5 \mathrm{~g} / \mathrm{dL}$ (iv) $>15.5 \mathrm{~g} / \mathrm{dL}$

C. Min Weight: (i) $>40 \mathrm{~kg}$ (ii) $>45 \mathrm{~kg}$ (iii) $>50 \mathrm{~kg}$ (iv) $>55$ $\mathrm{kg}$

D. Pulse: (i) $80-120 \mathrm{bpm}$ (ii) $100-130 \mathrm{bpm}$ (iii) $50-80 \mathrm{bpm}$ (iv) $50-100 \mathrm{bpm}$

E. BP: SBP (i)100-150 (ii) 100-180 (iii) 90-120 (iv) 110-140 DBP (i) 60-100 (ii) 50-80 (iii) 70-90 (iv) 50-100

4. Write Indications for the Following

(A) Indication for transfusion of whole blood:

(a)

(b)

(B) Indication for transfusion of packed cells:

(a)

(b)

(C) Indication for transfusion of FFP:

(a)

(b)

(D) Indication for transfusion of platelets:

(a)

(b)

(E) Indication for transfusion of cryoprecipitate:

(a)

(b)

(F) Indication for saline washed packed cells:

(a)

(b)

5. Write the Transfusion Dose for the Following Components

(a) Packed cell-

(b) Platelets-

(c) FFP-

(d) Cryoprecipitate-

6. All are Contraindications for Transfusion of Platelets Except

(a) Patients with rapid platelet destruction associated with ITP.

(b) Patients with Heparin-Induced Thrombocytopenia (HIT)

(c) Volume replacement.

(d) Patients with Thrombotic Thrombocytopenic Purpura (TTP).

\section{All are Contraindications for Transfusion of FFP} Except

(a) Disseminated intravascular coagulopathy.

(b) Treatment of hypovolemia without coagulation factor deficiencies.

(c) When coagulopathy can be more appropriately corrected with specific therapy such as vitamin K.

(d) Volume replacement alone or for a single coagulation factor deficiency. 
8. Contraindication of Cryoprecipitate Transfusion are all Except
(a) In the treatment of haemophilia, A or in most cases in the treatment of von Willebrand's disease.
(b) Used to make fibrin glue.
(c) Laboratory studies indicate a fibrinogen concentration of $1.0 \mathrm{~g} / \mathrm{L}$ or less.
(d) Thrombotic thrombocytopenic purpura.

9. Can a Patient with Blood Group $\mathrm{Rh}+$ be Transfused with a Blood Bag of Rh- Blood Group?

(a) Yes. (b) No.

10. In what temperature range are the following blood and blood components stored?
A. Whole blood: (i) $1-6^{\circ} \mathrm{C}$ (ii) $7-10^{\circ} \mathrm{C}$ (iii) $11-14^{\circ} \mathrm{C}$ (iv) $18-22 \circ \mathrm{C}$
$\begin{array}{llll}\text { B. } & \text { Packed cell: (i) } 1-6^{\circ} \mathrm{C} & \text { (ii) } 7-9^{\circ} \mathrm{C} & \text { (iii) } 10-12^{\circ} \mathrm{C}\end{array}$ (iv) $14-16^{\circ} \mathrm{C}$
C. Platelets: (i) $6-10^{\circ} \mathrm{C}$ (ii) $12-18^{\circ} \mathrm{C}$ (iii) $20-24^{\circ} \mathrm{C}$ (iv) $28-32 \circ \mathrm{C}$
D. Cryoprecipitate: (i) $-4^{\circ} \mathrm{C}$ (ii) $-7^{\circ} \mathrm{C}$ (iii) $-10^{\circ} \mathrm{C}$ (iv) $-30^{\circ} \mathrm{C}$
E. FFP: (i) $-4^{\circ} \mathrm{C}$ (ii) $-7^{\circ} \mathrm{C}$ (iii) $-10^{\circ} \mathrm{C}$ (iv) $-30^{\circ} \mathrm{C}$

11. Administration Guidelines

(a) Within how much time, infusion of the following blood components should be started?

1. Packed cell- (i) $80 \mathrm{~min}$. (ii) $30 \mathrm{~min}$. (iii) $40 \mathrm{~min}$. (iv) $60 \mathrm{~min}$.

2. Platelet concentrate- (i) Immediately (ii) $20 \mathrm{~min}$. (iii) $30 \mathrm{~min}$. (iv) $60 \mathrm{~min}$.

3. FFP- (i) Immediately (ii) $30 \mathrm{~min}$. (iii) $40 \mathrm{~min}$. (iv) $60 \mathrm{~min}$.

(b) Within how Much Time, Infusion of The Following Blood Components Infusion To Be Completed?

1. Packed cell- (i) $2-4$ hrs. (ii) 5-8 hrs. (iii) $9-12 \mathrm{hrs}$. (iv) $30 \mathrm{~min}$.

2. Platelet concentrate- (i) $15-20 \mathrm{~min}$. (ii) $30-60 \mathrm{~min}$. (iii) $80-120 \mathrm{~min}$. (iv) $4 \mathrm{hrs}$.

3. FFP- (i) $15-20 \mathrm{~min}$. (ii) 30-60 min. (iii) 80-120 min. (iv) $4 \mathrm{hrs}$.

4. How will you manage case of?

(i) Mild transfusion reaction.

(ii) Moderate transfusion reactions.

(iii) Life-threatening transfusion reaction.

5. A BT set should be changed after how much time of starting the Blood Transfusion?

(i) 4 hrs. (ii) 6 hrs. (iii) 10 hrs. (iv) 12 hrs.

6. In case of Emergency, how will you communicate cross match and issue request for blood and its Components to the Blood Bank?

3. Donor selection criteria

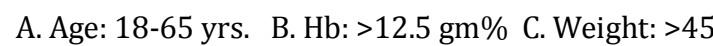
Kgs.

D. Pulse: 50-100 bpm, regular E. BP: SBP :100 - 180, DBP : 60-100.
4. Write Indications for the Following

(A) Indication for Transfusion of Whole Blood
(a) Massive haemorrhage.
(b) Exchange transfusion in neonates.

(B) Indication for transfusion of packed cells
(a) Symptomatic anaemia $(\mathrm{Hb}<7 \mathrm{~g} / \mathrm{dL})$
(b) Post-chemotherapy/Radiotherapy $(\mathrm{Hb}<9-10 \mathrm{~g} / \mathrm{dL})$.

(C) Indication for transfusion of FFP
(a) DIC.
(b) TTP.

(D) Indication for transfusion of platelets
(a) Thrombocytopenia.
(b) Platelet function abnormality.

(E) Indication for transfusion of cryoprecipitate
(a) Haemophilia.
(b) Hypofibrinogenemia.

(F) Indication for saline washed packed cells
(a) Thalassemia.
(b) Severe allergic reactions.

5. Write the transfusion dose for the following components

(a) Packed cell - 1 unit raise $\mathrm{Hb}$ by $1 \mathrm{gm} \%$ and Hematocrit by $3-5 \%$.

(b) Platelets - $15 \mathrm{~mL} / \mathrm{kg}$ body weight for children $<20 \mathrm{~kg}$; therapeutic dose (5-6 units RDP or 1 SDP) for adults and older children.

(c) FFP - 4 units in the adult; $10-15 \mathrm{~mL} / \mathrm{kg}$ body weight in children.

(d) Cryoprecipitate - $12-15 \mathrm{~mL} / \mathrm{kg}$ body weight equivalent to 4 units for an adult.

6. (c) Volume replacement.

7. (a) Disseminated intravascular coagulopathy.

8. (d) Thrombotic thrombocytopenic purpura.

9. Yes.

10. Storage temperature for blood and blood components

A. Whole blood: $1-6^{\circ} \mathrm{C}$.

B. Packed cell: $1-6^{\circ} \mathrm{C}$.

C. Platelets: $20-24{ }^{\circ} \mathrm{C}$.

D. Cryoprecipitate: $-30{ }^{\circ} \mathrm{C}$.

E. FFP: $-30^{\circ} \mathrm{C}$.

11. Administration Guidelines Correct Match

(a) Within how much time infusion of the following blood components should be started?

1. Packed cell - $30 \mathrm{~min}$.

2. Platelet concentrate - Immediately.

3. FFP - $30 \mathrm{~min}$.

(b) Within how much time infusion of the following blood components infusion to be completed?

(1) Packed cell - 2-4 hrs.

(2) Platelet concentrate - 30-60 min.

(3) FFP - 30-60 min.

12. How will you manage case of?

(i) Mild transfusion reaction - Administer antihistaminics after the patient is stable, continue the transfusion with same bag.

(ii) Moderate transfusion reactions - Administer anti-histaminics and IV steroids, return the bag to the blood bank for post-transfusion workup. 
(iii) Life-threatening transfusion reaction Administer adrenaline, steroids and diuretic, return the bag to the blood bank for posttransfusion workup.

13. Guidelines for BT SET: $4 \mathrm{hrs}$

14. Protocol for emergency issue

In emergency situation it is very important to have clear communication between blood bank and clinical areas; for this purpose, following terminology should be used.

Urgent - Issue of blood bag within 30 minutes by using advanced technique of cross-matching.

Extremely Urgent - Issue of blood bag required within 15 minutes, group specific/O Negative/O positive packed cells are issued within 15 minutes without cross match. (Cross match procedure is started and results are informed within 30-40 minutes).

Telephonic Request - Telephonic request is acceptable in emergency situations when sample of the patient is available with the blood bank along with proper documentation completed later on. This is documented by the blood bank and in the patient's medical records by the requesting doctor. The following minimum information must be given and confirmed:

Name of the doctor calling and his/her designation.

Patient's Name and ID.

Location.

Number/volume and type of component.

Reason for request.

\section{REFERENCES}

1. Fantus B. The therapy of cook county hospital. JAMA 1937;109:128-31.

2. Gharehbaghian A, Javadzadeh Shahshahani H, Attar M, et al. Assessment of physician's knowledge in transfusion medicine, Iran. Transfus Med 2009;19:1328.

3. Rothschild JM, Mc Gurk S, Honour M, et al. Assessment of education and computerized decision support interventions for improving transfusion practice. Transfusion 2007;47(2):228-39.

4. Tinmouth A, Macdougall L, Fergusson D, et al. Reducing the amount of blood transfused: a systematic review of behavioural interventions to change physician's transfusion practices. Archives of Internal Medicine 2005;165(8):845-52.

5. Panzer SS, Engelbrecht MF, Cole-Sinclair E Wood MS, et al. Education in transfusion medicine for medical students and doctors. Vox sanguinis 2013;104(3):25072.
6. Greco PJ, Eisenberg JM. Changing physician's practices. N Engl J Med1993;329(17):1271-3.

7. Bryant BJ, Alperin JB, Indrikovs AJ. Blood bank on call physician's experiences at a large university medical centre. Transfusion 2005;45(1):35-40.

8. Rock G, Berger R, Pinkerton P, et al. A pilot study to assess physician knowledge in transfusion medicine. Transfus Med 2002;12(2):125-8.

9. Follea G. Training and education in Europe. ISBT Science series 2007;2(1):58-61.

10. Mozes B, Epstein M, Ben-Bassat I, et al. Evaluation of the appropriateness of blood and blood product transfusion using present criteria. Transfusion 1989;29(6):473-6.

11. Surgenor DM, Wallace EL, Hao SH, et al. Collection and transfusion of blood in the United States, 1982-1988. N Engl J Med 1990;322(23):1646-51.

12. Goodnough LT, Johnston MF, Toy PT. The variability of transfusion practice in coronary by pass surgery transfusion medicine academic award group. Journal of American Medical Association 1991;265(1):86-90.

13. Salem-Schatz SR, Avorn J, Soumerai SB. Influence of knowledge and attitudes on the quality of physicians' transfusion practice. Med Care 1993;31(10):868-78.

14. Wu WC, Rathore SS, Wang Y, et al. Blood transfusion in elderly patients with acute myocardial infarction. N Engl J Med 2001;345(17):1230-6.

15. Hebert PC, Fergusson DA. Do transfusions get to the heart of the matter? JAMA 2004;292(13):1610-2.

16. Rao SV, Jollis JG, Harrington RA, et al. Relation-ship of blood transfusion and clinical outcomes in patients with acute coronary syndromes. JAMA 2004;292(13):155562.

17. Smith BR, Aguero-Rosenfeld M, Anastasi J, et al. Educating medical students in laboratory medicine: a proposed curriculum. Am J Clin Pathol 2010;133(4):533-42.

18. Salem-Schatz SR, Avorn J, Soumerai SB. Influence of clinical knowledge, organizational context, and practice style on transfusion decision making implications for practice change strategies. JAMA 1990;264(4):476-83.

19. Mitchell SA, Strauss RG, Albanese MA, et al. A survey to identify deficiencies in transfusion medicine education. Acad Med 1989;64(4):217-9.

20. Tinmouth A. Reducing the amount of blood transfused by changing clinician's transfusion practices. Transfusion 2007;47(s2):132S-6S.

21. Salimi S. Evaluation of graduated medical student's knowledge in transfusion medicine final report of research project. Iranian blood transfusion organization, research centre, 2005. 